\title{
The Center of Effort and the Countermeasures to Improve the Independent Innovation Ability of Employees
}

\author{
Tian-ming Xiao, Guotie Chen, Aihua Wu \\ Fujian University of Technology,Fujian Fuzhou China 350108 \\ xtm-9@163.com
}

\begin{abstract}
Keywords: Independent Innovation. Lean Culture. Employee.
Abstract. In order to improve the employees' Independent Innovation Ability, the enterprises should hold a key. The key elements to Improve Employee Innovation Ability that are Employees' Independent Innovation Consciousness and intention, Employees' Independent Innovation spirit and quality, Employees' Independent Innovation Knowledge and skills. Then clearly puts forward the Focus Point to improve Employees' Independent Innovation Ability.And put forward some Suggestion of countermeasure to Improve Employees' Independent Innovation Ability high efficiently tightly around the focus point.
\end{abstract}

\section{Introduction}

Employees are the most important resource in the enterprises. Employees are the pillars for enterprises' independent innovation.It is important for enterprises to improve the staff's independent innovation ability. Improving the independent innovation ability of the staff is the key to improve the independent innovation ability of the enterprises.

Yingxin Deng(2011 $)^{[1]}$ Point out the key of the competition of enterprises is the competition of the staff. The independent innovation of enterprises' employees is the guarantee for the continuous innovation and development of enterprises. Bai Jia (2012) ${ }^{[2]}$ pointed out the important significance of the independent innovation ability of the small and medium enterprises to enhance the independent innovation ability of the staff.The internal factors and external factors to impact the staff's independent innovation ability were analysed.

At present, there is still a lack of research on improving the independent innovation ability of the staff in our country. In this paper, the key elements of improving the independent innovation ability of the staff are caught.The center of effort and the counternmeasures to improve the independent innovation ability of employees are pointed out.The enterprises will improve the independent innovation ability effectively by the key points.

\section{The key elements of improving the independent innovation ability of employees}

The connotation of independent innovation ability of Employees is the ability for the staff to improve the quality and effectiveness of independent innovation, which may have been demonstrated or potential.

Employees' independent innovation ability is invisible which can be influenced by the invisible force. Many companies mistakenly believe that the key factors to improve the innovation ability of employees is the funds, equipment and other external conditions.In fact,The staff with strong independent innovation ability can often use individual and collective wisdom to create a miracle in the absence of resource and obtain excellent achievements. The funds, equipment and other external conditions are indispensable, but it is not the key to improve the independent innovation ability of employees. The staff 's independent innovation can be "potential" form . The staff 's independent innovation can be used by enterprises at any time. The key is whether your enterprise employees have independent innovation ability. The Enterprise managers should pay great attention to the 
improvement of employees'independent innovation ability in the daily management, so that it can be fully played in various independent innovation. The three key elements to raise employees' independent innovation ability are the independent innovation consciousness of the staff, employees' independent innovation spirit quality and the knowledge and skills of employees' Independent Innovation.

\section{The independent innovation consciousness of the staff}

The independent innovation consciousness of the staff is the subjective consciousness, desire and enthusiasm of the employees' participation in independent innovation. Employee independent innovation consciousness is the basic key factor to improve the independent innovation ability.Only with a strong sense of independent innovation, employees may have a strong desire to participate in independent innovation, to raise and use independent innovation ability forwardly, and to achieve independent innovation results by efforts.

\section{Employee independent innovation spirit quality}

Employees' independent innovation spirit quality includes excellent spirit quality,such as constant, diligence, perseverance, continuous improvement, the pursuit of perfection, flexible innovation, the courage to break. The process of independent innovation is a difficult process. The staff without the innovation spirit quality is very easy to give up halfway. Employee independent innovation spirit quality is the fundamental key element to improve the independent innovation ability.

\section{The knowledge and skills of employees' Independent Innovation}

The knowledge and skills of employees' Independent Innovation refers to the skills and ability for the staff to learn knowledge,mastery,flexibly integrate knowledge, innovate knowledge and overcome technical difficulties by comprehensive application of knowledge. The knowledge and skills of employees' Independent Innovation is an important guarantee to improve the independent innovation ability of the employees.So the knowledge and skills of employees' Independent Innovation is the indemnificatory key element to improve the independent innovation ability ${ }^{[3]}$.

\section{The center of effort to improve the independent innovation ability of employees}

The center of effort to improve the independent innovation ability of employees is the key emphasis in work to raise the staff's independent innovation ability. At present, most enterprises have realized the importance of improving the independent innovation ability.But many enterprises has not caught the focus of the work, so that there are more blind and with more waste in the practice.In order to improve the independent innovation ability, we must seize the key elements of improving the independent innovation ability, and then make clear the focus of improving the independent innovation ability of the staff.

Based on the above analysis, we can clear that the center of effort to improve the independent innovation ability of employees is to raise the independent innovation consciousness of the staff, employee independent innovation spirit quality and the knowledge and skills of employees' Independent Innovation.

\section{Suggestions on the countermeasures to improve employees' Independent Innovation ability}

Countermeasures and suggestions to improve employees' Independent Innovation ability must focus on the center of effort to improve the independent innovation ability of employees.

\section{Build Lean enterprise culture}

Enterprise culture and independent innovation ability is interactive ${ }^{[4-5]}$ Enterprise culture has many functions which can not be replaced by traditional management,such as the function of guidance, motivation, and standardization and so on. We can enhance the independent innovation ability of employees directly or indirectly by using the functions of corporate culture ${ }^{[6]}$. Enterprise culture, as the cultural atmosphere in the whole enterprise, has an improtant influence on the 
enterprise spirit, enterprise values, enterprise philosophy, enterprise products and services, enterprise technological innovation, enterprise material environment, enterprise employee behavior, corporate leadership, enterprise system, enterprise organization structure, etc. Excellent enterprise culture can simultaneously improve employee's Independent Innovation consciousness, spirit quality,knowledge and skills.

Lean enterprise culture refers to the business spirit, values, business philosophy, ethics, behavior criteria, management system, corporate image, etc. based on Lean Thinking. Lean enterprise culture emphasize customer demand as the center, eliminate all waste, excellence, continuous improvement and pursuit of perfection. Lean enterprise culture create Line staff . At the same time, lean enterprise culture improves the lazy employees with an invisible force. Even if the new employees can also have an invisible education and infection. Lean enterprise culture has powerful force of transformation to improve the employees' independent innovation consciousness and independent innovation spirit quality.

To build lean enterprise culture is a process of gradual process. Though many enterprises can't achieve establishing a comprehensive Lean enterprise, because it is neceary to consume huge amounts of money ,the enterprises can build Line enterprise culture though introducing Lean concept. Enterprises' managers should take the lead in systematic study of Lean Thinking and its related theories, methods and techniques. For example, the managers promote the lean thinking into the knowledge system of the staff by using training, publicity,guidance, or to other enterprise for learning Lean way according to the actual situation of enterprise application. The important Lean concept,such as "customer demand as the center", "eliminate all waste", "excellence and continuous improvement" and so on,should be emphased on the promotion of good cultural atmosphere in the whole enterprises. Then, to revise and consolidate constantly. At last,A unique Line culture can form in the enterprises which can affect everyone in the enterprises ${ }^{[7]}$.

\section{Line-Flexible motivation}

Motivation is the application of a certain method to stimulate, encourage, mobilize, strengthen the work motivation, enthusiasm and creativity of employees,so that employees can achieve the organizational goals with full potential. Scientific motivation is an effective way to improve the independent innovation consciousness of the staff, employees' independent innovation spirit quality and the knowledge and skills of employees' Independent Innovation.

What kind of motivation is science? The traditional rigid motivation models are gradually recognized as "effect is limited".the modern people pay more and more attention to the use of emotional motivation, spiritual motivation and other flexible incentive models. In fact,both rigid motivation and flexible motivation have some limitations. The more scientific incentive way should be Line-flexible motivation, which is the combination of rigid and flexible.

To the implementation of Line-Flexible motivation,the managers should be both targeted and open-minded.They should meet employees' psychological needs according to practical situation。 They must pay attention to the excitation by system, but also pay attention to the excitation outside the system. The incentive effect should be emphasized. The material incentive should be appropriate in order to avoid the waste caused by excessive incentives. They should be good at reverse thinking and take the motivate target as "pull" source.They should take flexible and diverse motivational behavior based on the demand of employees .

\section{Example rendering}

The willingness of the staff, the spirit quality and the knowledge of the staff can be all affected each other. Most of the time, the managers' teaching with little success. But the application of " example rendering " and the mutual "biography, help, with" among the staff can has better effect.

To promote everyone to innovation, the enterprises should not only pay attention to the overall publicity,but also be good at using "example rendering". The managers should be good at discovering employees who are excellent in Independent Inovation and set up them as example who can be given 
special treatment and reward.Through the example rendering,other employees will be driven to Independent Inovation.

\section{The implementation of the "science and technology improve enterprises" concept}

The concept of "Science and technology improve enterprises" has been proposed for a long time, but many enterprises regard it as a "slogan" or form and ignore the implementation of this concept.So many enterprises' employees are lack of the concept of "Science and technology improve enterprises", which hinders the staff to raise the awareness to take part in Independent Innovation .

Enterprises should not only propaganda the concept of "Science and technology improve enterprises" in meetings, training, daily work and so on, but also take the concept of "Science and technology improve enterprises" to practice.During the implementation of the concept of "Science and technology improve enterprises ", employees should be clear that scientific and technological innovation is a gradual accumulation and not to give up because of small innovation or difficult process.

\section{Driven by innovation}

The process of Independent Inovation work of enterprises is also the important process to raise the independent innovation consciousness of the staff, employees' independent innovation spirit quality and the knowledge and skills of employees' Independent Innovation.

When employees of the enterprises are less willing to Independent Inovation, it is necessary to adopt the mandatory way, such as "instruction promotion" and "system rewards and punishment". The propagand,training and encouragement should be strengthened at the same time,so that employees can participate in Independent innovation consciously or unconsciously.

The managers should attach great importance to the feedback information of the Independent innovation project team. The problems should be corrected in time once they are found. The managers guide, encourage and promote Independent innovation project team to break through a variety of difficulties, so that employees get exercise in Independent innovation practice. The obstacles of consciousness, mental quality, knowledge and skills will be overcome a step by step.

\section{Conclusions}

In short, we must identify the focus point in order to do any work efficiently. Similarly, we must also find the focal point to improve employees'Independent Innovation ability. This paper points out three key focus points to raise employees' t'Independent Innovation ability and put forward a series of Suggestions on the countermeasures to improve employees' Independent Innovation ability. So that enterprises can improve the quality and efficiency to raise the Independent Innovation ability of staff.

\section{Acknowledgements}

This work was financially supported by the National Social Science Project (12BGL015).

\section{References}

[1]Yingxin Deng. Effective Ways to Enhance the Independent Innovation Ability of Employees[J]. Value Engineering, 2011(35):127-128. (in Chinese)

[2]BaiJia. Research on the independent innovation ability of small and medium enterprises[J]. Shandong Agricultural Sciences,2012,44(11):135-137.(in Chinese)

[3]Tianming Xiao.Lean-Flexible Thinking and Lean-Flexible Management_- The Innovation of Thinking and Scientific Management in the New Economic Era[M]. China Economic Publishing House, 2012. (in Chinese)

[4]Sebastian Bittmann..Socioinformatics - The Social Impact of Interactions between Humans and IT [M]. Springer International Publishing,2014:1-12. (in Chinese ) 
[5]Tianming Xiao.Research on the interaction between the Line-flexible enterprise culture and the technological innovation of enterprises[J].Science \&Technology Progress and Policy,2012(19):17-21. (in Chinese)

[6]Wang Shuai, To furtherly improve the independent innovation ability of employees based on enterprise culture $[\mathrm{J}]$. Technology and enterprise, 2012(02):164. (in Chinese )

[7] Tianming Xiao .Application of Lean Thinking Fashion in Architectural Enterprises for

Self-innovation[J]. Science and Technology Management Research,2010(14):140-142,126. （in Chinese)

Author brief introduction: Tianming Xiao ( 1973 - ), female, the Han nationality, Fujian University of Technology, professor, Doctoral student of Chongqing University, research on direction for management science.

Guotie Chen(1975-), male, the Han nationality, Fujian University of Technology, associate professor, Dr. , research on direction for management science.

Aihua Wu(1975-), male, the Han nationality, Fujian University of Technology, lecturer, Master, research on direction for management science. 